Doi: HTTPS://DOI.ORG/10.23910/IJBSM/2017.8.1.1674

\title{
Cassia Gum an Environment-friendly Alternative Thickener in Printing with Natural Dyes
}

\author{
Sandeep Bains* and Manisha Sethi
}

Dept. of Apparel and Textile Science, College of Home Science, Punjab Agricultural University, Ludhiana (141001) India

\author{
Corresponding Author \\ Sandeep Bains \\ e-mail: sandeepct@pau.edu
}

\author{
Article History \\ Manuscript No. AR1674 \\ Received in $5^{\text {th }}$ Sep, 2016 \\ Received in revised form $27^{\text {th }}$ Jan, 2017 \\ Accepted in final form $6^{\text {th }}$ Feb, 2017
}

\begin{abstract}
Natural dyes and natural thickening agents appear to be ideal choice for printing the fabric. This is because natural dyes and thickening agents have better biodegradability and higher compatibility with environment. In addition to this, interest in the use of natural dyes and thickening agents has been growing rapidly due to the result of stringent environmental standards imposed by many countries in response to toxic and allergic reactions associated with synthetic dyes. The aim of present work has been carried out to prepare eco-friendly natural dye printing paste from the Arjun dye Bark extract using natural thickening agent i.e. Cassia tora seed gum. The trials were under taken to block print desized cotton fabric with the prepared printing paste. The recipe was optimized using $2.5 \%$ and $5 \%$ of concentration of the gum and the best concentration was determined. Two mordants, 5\% Alum and $2 \%$ Ferrous Sulphate were selected for obtaining change in shade and improvement of colour fastness properties. The block printed samples were evaluated for visual evaluation, colour fastness properties and CIE Lab values. Results of cotton block printed samples with both the mordants exhibited excellent to very good fastness rating for light, washing, rubbing and perspirations. Thus, it was concluded that cotton fabric can be successfully block printed using $5 \%$ of natural thickening agent.
\end{abstract}

Keywords: Natural dye, thickener, Cassia tora gum, cotton, printing

\section{Introduction}

Increased awareness of people about harmful effects of synthetic dyes and thickers, use of natural sources has geared up in the modern times. Green minded and health conscious consumers go for fabrics dyed and printed with natural dyes (Saroj Yadav and Geeta Gaba, 2016). Plant products are effective alternative to synthetic products as these are biocompatible, have low toxicity, environment friendly and low in cost as to synthetic products. Natural thickening agents procured from plants are also non-polluting renewable sources for the sustainable supply (Sudha Babel and Rupali Gupta 2016). Thickener is a thick mass which imparts stickiness and plasticity to the print paste so that it is suitable to be applied on the fabric surface without bleeding or spreading. These should also be capable of maintaining the design out lines (Mazharul Islam Kiron, 2014, Sudha Babel, Hema Upadhayay and Rupali Gupta, 2015), the thickener needs to be colourless to avoid imparting its own colour. These must be stable, compatible with the dye auxiliaries used, good adhesion, and minimum effect on colour yield and with acceptable cost.

The purpose of thickener is accomplished only, if it provides viscosity to the print paste preventing premature reactions between the chemicals contained in the print paste and holding the ingredients of the print paste on the fabric.

Thickener or print pastes are traditionally made by dissolving the colorants and auxiliary chemicals and then stirring them into the required weight of pre-prepared thickener. Since long printers have been using thickeners optimized by trial and error methods, experience and subjective judgments. Now that the chemistry and physics of polymers are better understood, it is possible to select and use them more scientifically. These days there is availability of a wider range of thickening agents, including synthetic and natural polymers. Thickening agents mainly used for preparation of print paste are starch derivatives, flour, GumArabic, Guar derivatives, tamarind, sodium alginate, sodium polyacrylate, gum Senegal and gum tragacanth, British gum or dextrine and albumen.

Cassia tora is a wild crop, grown in hot, wet, tropical parts of India as a weed and now commercially used as natural gelling agent in industrial applications. It contains $1-2 \%$ volatile cassia oil, which is mainly responsible for the spicy aroma and taste. The primary chemical constituents of Cassia include cinnamaldehyde, gum, tannins, mannitol, coumarins, and essential oils; it also contains sugars, resins, and mucilage, among other constituents (Anonymous, 2016). In this study 
an attempt was made to use Cassia Tora L. as an alternative thickening agent in the printing paste, which belongs to leguminosae family.

\section{Material and Methods}

\subsection{Study site}

The trials of the research work were carried during the year 2015, in the Department of Apparel and Textile Science, Punjab Agricultural University, Ludhiana.

\subsection{Selection and preparation of raw material}

Pure cotton fabric was procured from local market and scoured to remove the impurities. Fabric was boiled for $45 \mathrm{~min}$. in a solution containing 2 grams of nonionic detergent and one gram of $\mathrm{NaOH}$ per liter of water. After kneading and squeezing, the samples were rinsed under tap water, shade dried and ironed. Then the fabric was pretreated with $20 \%$ of myrobalan solution for 24 hours maintaining the 1:20 MLR (material to liquor ratio). The fabric was squeezed in both warp and weft direction and sun dried. The side not exposed to sunlight was darker and was used for printing. Same concentration of myrobalan (20\%) was used during dyeing of cotton with Arjun dye as the percent dye absorption was highest (Grewal and Bains, S., 2002).

Bark of Arjun tree (Terminalia arjuna) was chosen as a source of natural dye. Arjun Bark was dried in shade, grounded to powder and used as a dye source in the standardized printing paste. The printing paste was prepared by soaking 100 gms of Arjun bark dye powder in $1000 \mathrm{ml}$ of distilled water overnight. The solution was sieved from two layers of muslin fabric and boiled until $50 \mathrm{ml}$ of the extract was left. The required amount of cassia tora gum ( $0.25 \mathrm{~g}$ or $0.50 \mathrm{~g}$ ) was mixed in $10 \mathrm{ml}$ of luke warm water. The mixture was kept undisturbed for 15 minutes and boiled for 2-3 minutes.

Cassia tora seeds were utilized as natural thickening agent for the study. After removing dirt and dust, raw material the seeds were subjected to de-husking and splitting process. Finally the splits were ground to fine powder. Gum of selected concentration ( $2.5 \%$ and $5.0 \%$ of gum) was mixed/ soaked in 10 $\mathrm{ml}$ of luke- warm water separately and kept undisturbed for 15 minutes. The measured amount of dye concentrate was added and heated till the semi liquid translucent consistency was achieved. The paste was removed from heat. Two mordants (5\% Alum and 2\% Ferrous Sulphate) were used for the study. Each mordant was used at two different concentrations of natural thickening gum i.e. $2.5 \%$ and $5 \%$. Mordants are metal salts which provide exhaustion and fixation of printing paste to textile materials. In natural dyes colour change expectations is somewhat high and effect of mordant type is of great importance for the shade of the colour (Samanta and Agarwal, 2009). Two drops of fixer was added in the printing paste to fix the colour onto the fabric.

The prepared printing paste was uniformly scattered on the foam (double layered) spread on the tray and block printing was done on desized and myrobalan pretreated cotton fabric. The fabric was then dried and after 24 hours it was kept at $70-80{ }^{\circ} \mathrm{C}$ for 5 minutes in a hot air oven chamber. The fabric was dried under shade and washed under running water.

\subsection{Assessment of printed samples}

The printed samples were evaluated for colour fastness to light, washing, rubbing and perspiration by following standard procure laid down by Bureau of Indian Standards No. washing fastness IS: 3361-1979 Anonymous (1979), light fastness IS: 2454-1985 Anonymous (1985) and rubbing fastness IS: 7661988 Anonymous (1988). The CIE Lab values Anonymous (2003) for all the block printed samples were done with illuminant D 65 and $10^{\circ}$ observer.

\section{Results and Discussion}

3.1. Colour fastness on cotton printed with Arjun dye using 2.5\% Cassia tora gum

Light fastness grades for block printed samples, using 2.5 percent Cassia tora gum and no mordant was very good and rated 6 grade. Whereas, the samples printed by adding 5 percent Alum and $2 \%$ ferrous sulphate mordants separately in print paste, the light fastness grade was good and rated with 5 grades (Table 1 and Figure 1). The washing fastness grade for colour change samples printed using no mordant was $4 / 5$. The rating was very good (5) for both the samples printed using 5 percent Alum and $2 \%$ ferrous sulphate mordants separately in print paste. No colour staining was observed on all the samples when $2.5 \%$ Cassia tora gum was added in print paste.

The rubbing fastness grades for colour change for dry rubbing, when no mordant was added was good and ranked 4. As regards the grades for colour change for wet rubbing, when no mordant was added, was poor and ranked 2 . When $5 \%$ Alum and $2 \%$ ferrous sulphate mordants were separately adding in print paste the grades improved to excellent $(4 / 5$ and 5 respectively) for both dry and wet rubbing. There was noticeable staining (3) in dry rubbing for samples printed using $2.5 \%$ gum when no mordant was used in the print paste. Negligible staining (4/5) was observed when alum was added, but decreased to considerable staining when ferrous sulphate mordant was added. Whereas in the case of wet rubbing the samples were heavily stained when no mordant was added, slightly stained (4) when alum was added and considerable staining when ferrous sulphate mordant was added.

The perspiration grades in both acidic and alkaline condition conditions for colour change was excellent and ranked 5 when no mordant was added. Colour increase was observed when $5 \%$ alum was added. The grade was good (4) when $2 \%$ ferrous sulphate ordant was added in print paste. Colour staining in acidic condition on both wool and cotton for all the samples ranged between noticeable to no staining. There was negligible (4/5) staining on wool and slight (4) staining on cotton when no mordant was added. Whereas, in alkaline 
condition slight staining (3) was observed on both wool and cotton when $5 \%$ alum was added and negligible (4/5) staining

\begin{tabular}{|c|c|c|c|c|c|c|c|c|c|c|c|c|c|c|}
\hline \multirow{5}{*}{$\begin{array}{l}\text { Mordant conc. } \\
(\%)\end{array}$} & \multicolumn{14}{|c|}{ Colour fastness grades } \\
\hline & \multirow[t]{4}{*}{ Light } & \multicolumn{3}{|c|}{ Washing } & \multicolumn{4}{|c|}{ Rubbing } & \multicolumn{6}{|c|}{ Perspiration } \\
\hline & & \multirow{3}{*}{$\mathrm{cc}$} & \multicolumn{2}{|c|}{ CS } & \multicolumn{2}{|c|}{ Dry } & \multicolumn{2}{|c|}{ Wet } & \multicolumn{3}{|c|}{ Acidic } & \multicolumn{3}{|c|}{ Alkaline } \\
\hline & & & \multirow[t]{2}{*}{ w } & \multirow[t]{2}{*}{ c } & \multirow[t]{2}{*}{$\mathrm{cc}$} & \multirow[t]{2}{*}{ CS } & \multirow[t]{2}{*}{$\mathrm{cc}$} & \multirow[t]{2}{*}{ CS } & \multirow[t]{2}{*}{$\mathrm{cc}$} & \multicolumn{2}{|c|}{ CS } & \multirow[t]{2}{*}{ CC } & \multicolumn{2}{|c|}{ CS } \\
\hline & & & & & & & & & & w & $c$ & & w & $\mathrm{c}$ \\
\hline \multicolumn{15}{|c|}{$2.5 \%$ Cassia tora gum } \\
\hline Control & 6 & $4 / 5$ & 5 & 5 & 4 & 3 & 2 & $1 / 2$ & 5 & 5 & 5 & 5 & $4 / 5$ & 4 \\
\hline Alum $5.0 \%$ & 5 & 5 & 5 & 5 & $4 / 5$ & $4 / 5$ & $4 / 5$ & 4 & $\mathrm{Cl}$ & $4 / 5$ & $4 / 5$ & $\mathrm{Cl}$ & 3 & 3 \\
\hline $\mathrm{Fe}_{2} \mathrm{So}_{4} 2 \%$ & 5 & 4 & 5 & 5 & 5 & $2 / 3$ & 5 & $2 / 3$ & 4 & $4 / 5$ & $4 / 5$ & 4 & $4 / 5$ & $4 / 5$ \\
\hline \multicolumn{15}{|c|}{$5 \%$ Cassia tora gum } \\
\hline Control & 5 & 3 & $4 / 5$ & $4 / 5$ & $4 / 5$ & $4 / 5$ & $4 / 5$ & $4 / 5$ & 5 & 5 & 5 & 5 & $4 / 5$ & $4 / 5$ \\
\hline Alum $5.0 \%$ & 5 & 5 & 5 & 5 & $4 / 5$ & 5 & $4 / 5$ & 4 & $4 / 5$ & 4 & $3 / 4$ & 2 & 3 & $3 / 4$ \\
\hline $\mathrm{Fe}_{2} \mathrm{So}_{4} 2 \%$ & 5 & 4 & $4 / 5$ & $4 / 5$ & 5 & 3 & 5 & 3 & $\mathrm{Cl}$ & 5 & 5 & 5 & $4 / 5$ & $4 / 5$ \\
\hline
\end{tabular}

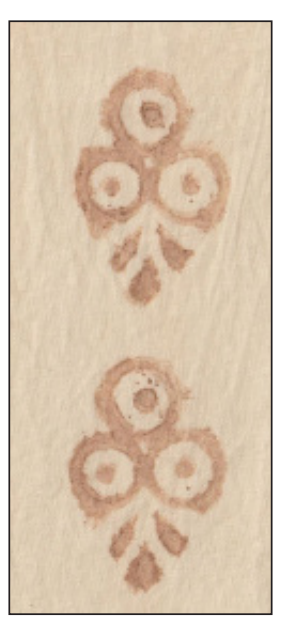

$1 \mathrm{~A}$

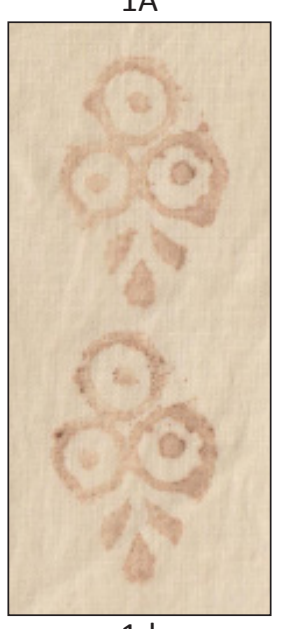

$1 \mathrm{~d}$

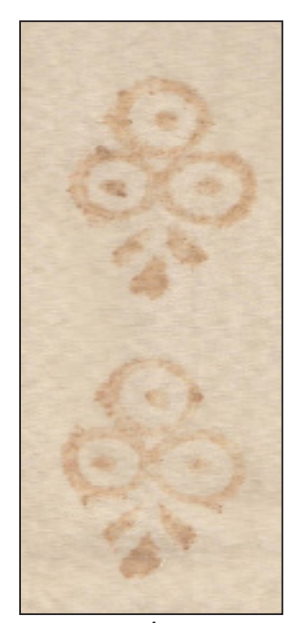

$1 b$

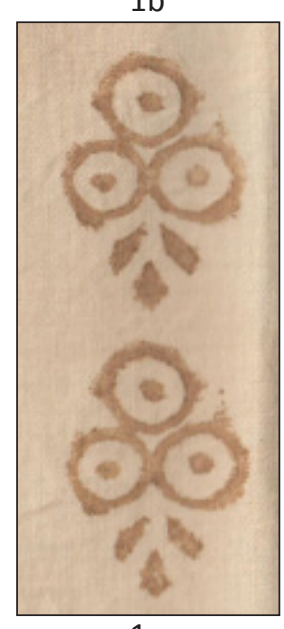

$1 \mathrm{e}$

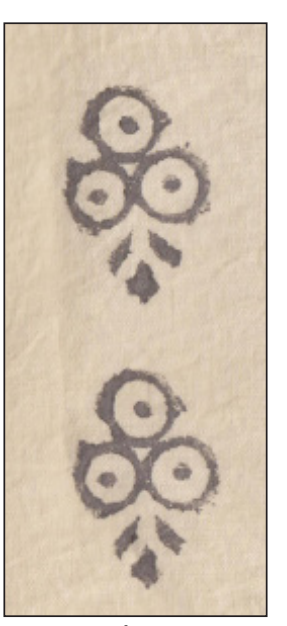

$1 \mathrm{c}$

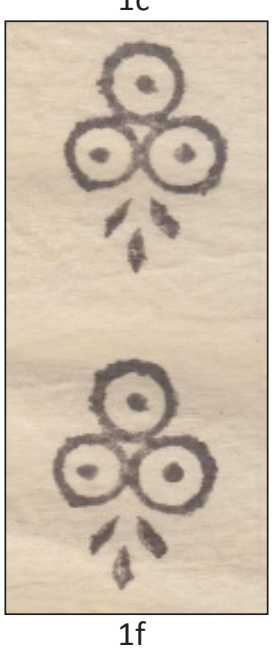

Figure 1: a: cassia $2.5 \%$ control; b: cassia $2.5 \%$ with alum; c: cassia $2.5 \%$ with ferrous; d: cassia $5 \%$ control; e: cassia $5 \%$ with alum; f: cassia $5 \%$ with ferrous

was observed on both wool and cotton when 2 percent ferrous sulphate mordant was added.

\subsection{Colour fastness on cotton printed with Arjun dye using 5\% Cassia tora gum}

The results for light fastness grades for block printed samples as shown in table 1 indicate that by using 5\% Cassia tora gum obtained good results for all the conditions and rated with grade 5 . The washing fastness grade for colour change was fair (3) for printed samples when no mordant was added, excellent (5) when $5 \%$ alum was added and good (4) when 2 percent ferrous sulphate mordant was added. The colour staining on both wool and cotton was negligible (4/5) when no mordant and $2 \%$ ferrous sulphate mordants were added in print paste separately. The samples showed no staining (5) when $5 \%$ alum was added.

The rubbing fastness grades for colour change during both dry and wet rubbing was excellent $(5-4 / 5)$ for all the conditions. There was negligible (4/5) colour staining for both dry and wet conditions, when no mordant was added. No staining (5) and slight (4) staining was observed for dry and wet rubbing respectively when $5 \%$ alum was added. There was considerable staining for samples with dry and wet rubbing with use of $2 \%$ ferrous sulphate mordant. Sudha Babel and Rupali Gupta (2013) also conducted similar study using flowers of Buteamonosperma and block printed cotton fabric. The perspiration grades in acidic conditions for colour change was excellent (5-4/5) when no mordant and 5 percent alum was added. Colour increase was observed when 2 percent ferrous sulphate mordants were added in print paste. In alkaline condition colour change observed was excellent (5) when no mordant and $2 \%$ ferrous sulphate was added. Poor (2) results were observed for $5 \%$ alum mordant. The results of staining ranged between noticeable to no staining (3-5) in acidic and 
alkaline condition on both wool and cotton.

The CIE lab values of the samples printed with $2.5 \%$ and $5 \%$ of Cassia tora gum with both the mordants have been presented in the Table 2. From the colour scale (CIE Lab) was analyzed, it was observed that the lower $L^{*}$ value of the sampled printed using Ferrous Sulphate were darkest for both the thickening concentrations. The higher $a^{*}$ value of the samples printed without using mordant was indicative of the fact that it was redder in colour as compared to other treatments. The yellowness of the samples printed using $5 \%$ alum mordant showed higher $b^{*}$ value with both the concentrations of the

Table 2: CIE values of block printed cotton fabric

\begin{tabular}{|c|c|c|c|c|c|c|}
\hline $\mathrm{CIE}$ values & \multicolumn{2}{|c|}{$\mathrm{L}^{*}$} & \multicolumn{2}{|c|}{$a^{*}$} & \multicolumn{2}{|c|}{$b^{*}$} \\
\hline $\begin{array}{l}\text { Concentra- } \\
\text { tion of gum }\end{array}$ & $2.5 \%$ & $5 \%$ & $2.5 \%$ & $5 \%$ & $2.5 \%$ & $5 \%$ \\
\hline $\begin{array}{l}\text { Control } \\
\text { (without } \\
\text { mordant) }\end{array}$ & 56.51 & 60.42 & 11.56 & 12.78 & 24.56 & 24.22 \\
\hline Alum (5\%) & 55.68 & 60.68 & 9.11 & 9.46 & 28.51 & 29.08 \\
\hline $\begin{array}{l}\text { Ferrous sul- } \\
\text { phate }(2 \%)\end{array}$ & 34.22 & 46.26 & 4.49 & 5.80 & 8.50 & 12.27 \\
\hline
\end{tabular}

thickening agent.

\section{Conclusion}

The study was undertaken to optimize the printing procedure with $1 \%$ Arjun dye on cotton fabric using Cassia tora gum with two concentrations ( 2.5 and $5 \%$ ). The best results were achieved using 5 percent cassia tora gum, along with the use of both 5 percent Alum and 2\% Ferrous Sulphate as mordants.

\section{Acknowledgement}

We acknowledge our sincere thanks to Directorate of
Research on Women in Agriculture, Bhubaneswar for the encouragement and financial support extended by them for the research.

\section{References}

Anonymous, 1979. Indian Standard method for determination of colourfastness IS: 3361-1979, Indian standards Institute, New Delhi.

Anonymous, 1985. Indian Standard method for determination of colourfastness IS: 2454-1985, Indian standards Institute, New Delhi.

Anonymous, 1988. Indian Standard method for determination of colourfastness IS: 766-1988, Indian standards Institute, New Delhi.

Anonymous, 2003. Color Flex ${ }^{R}$ User's Guide, Manual Version 2.3, Hunter Lab New Delhi.

Anonymous, 2016. https://en.wikipedia.org/wiki/Cassia_tora.

Babel and Gupta, 2016. Screen Printing on Silk Fabric using Natural Dye and Natural Thickening Agent, Journal of Textile Science and Engineering, 6, 230.

Mazharul, I. K., 2014. Printing Thickners / Functions or purpose of Thickener, Textile Learner Blog.

Grewal and Bains, S.,2002. Effect of After-Treatments on the fastness properties of cotton printed with Indian rhubarb, Journal of Research, 223, 384-399.

Samanta, A.K., Agarwal, P., 2009. Application of natural dyes on textiles, Indian Journal of Fibre and Textile Research 34, 384-399.

Babel, S., Upadhayay, H., Gupta, R., 2015. Optimization of Thickening Agent Based on Tamarind Seed Gum for Printing of Cotton and Its Impact on Physical Parameters, International Journal of Fiber and Textile Research, 5-8

Yadav, S., Gaba, G., 2016. Mango Kernel Starch- A Natural Thickener for Screen Printing on Silk With Kachnar Bark Dye. Global Journal for Research Analysis, 159-161. 